\title{
The role of parents' educational background in healthy lifestyle practices and attitudes of their 6-year-old children
}

\author{
Christina Stenhammar ${ }^{1}$, Anna Sarkadi ${ }^{2}$ and Birgitta Edlund ${ }^{1, *}$ \\ 'Uppsala University, Department of Public Health and Caring Sciences, Döbelnsgatan 2, SE- 75237 Uppsala, \\ Sweden: 'Uppsala University, Department of Women's and Children's Health, SE-751 85 Uppsala, Sweden
}

Submitted 9 March 2006: Accepted 18 November 2006: First published online 2 March 2007

\begin{abstract}
Objective: The aim of the present study was to examine parents' reported and desired frequencies (practices vs. attitudes) of their 6-year-old children's meals, nutritional intake and lifestyle components, as well as possible obstacles and desired support with respect to higher or lower educational backgrounds.

Design: Cross-sectional questionnaire study.

Setting: Five elementary schools in Uppsala, Sweden.

Subjects: Parents of 176 6-year-old pupils attending the first grade. The total response rate was $89.7 \%$.

Results: Parents with a college degree reported that their 6-year-olds had a higher frequency of milk, fruit and vegetable intake, more physical activity and fewer hours watching television compared with parents with a secondary school degree. Congruent to these differences in reported practices, more parents with a college degree desired a higher frequency of milk, fruit and vegetable intake, more physical exercise and less television viewing for their children. Regarding parents' desired meal frequencies during the week, no differences between the groups with higher and lower levels of education were found. Despite similar attitudes, however, parents with a college degree reported that their children ate mostly all meals significantly more often during the week. Both parent groups stated lack of time as the most common obstacle in providing their children with desired lifestyle practices, although parents with a secondary school education added lack of money as a contributing factor.

Conclusions: As attitudes are not always reflected in reported practices, it seems a fruitful approach to assess both, as well as obstacles perceived by parents, before planning interventions to enhance healthy lifestyle habits in children.
\end{abstract}

Keywords
Parents
Lifestyle
Practices
Attitudes
Educational background

The rising incidence of childhood obesity and related disorders necessitates the development of effective primary prevention strategies. There is now enough epidemiological evidence to support the correlation between overweight in 4-5-year-olds and overweight and obesity in later childhood and in adult life ${ }^{1-5}$. Therefore, primary prevention strategies should aim at pre-school children and their families. Because the home environment is crucial to children's health-related behaviour, knowledge about factors influencing parental practices is essential to make the implementation of primary preventive strategies for this age group possible. It seems rather consistent from the literature that parents' educational background and overall socio-economic status (SES) influence their lifestyle choices for their children in the expected direction ${ }^{6}$. Thus, a lower SES generally predicts a less healthy lifestyle in terms of nutrition, leisure and physical activities, resulting in increased risk for childhood obesity and later cardiovascular risk ${ }^{7,8}$. However, the pathway to these non-optimal parenting practices in low SES groups is not very clear. There is still the question of whether it is knowledge, attitudes or motivation, own unhealthy lifestyle practices, less optimal physical environment or perceived hindrances in executing plans for optimal lifestyle in their children that play the most significant role in the observed outcomes.

\section{Family SES and children's lifestyle}

Family SES seems to have an independent effect on adult health and health-related behaviour ${ }^{6-8}$. Even when controlling for adult social class and current lifestyle practices, childhood SES has an independent negative effect on adult obesity and cardiovascular health. Apart from this independent risk, there are the socially differing parenting practices that influence outcomes. Children in 
high SES families, for example, drink fewer soft drinks and consume more fruits, vegetables, high-fibre bread, cereals, vitamins and foods low in monounsaturated fats than children in low SES homes ${ }^{9,10}$. In addition, children of mothers with more education eat more vegetables ${ }^{11}$, and parents' higher education is associated with a more desirable level of nutrient and vitamin intake in children ${ }^{12}$. A qualitative study has pointed out that parents from lower SES groups are less likely to enforce food rules at home than higher SES parents, the former being more concerned with their children eating proper quantities of food ${ }^{13}$.

\section{The Swedish context}

In Sweden there is a strong social policy for promoting equity in health and social resources for the population. Therefore, primary preventive interventions and lifestyle information target parents of children broadly, as a whole group. Almost all parents (98\%) attend the maternal and child health centres and receive standard information there. Therefore, it can be assumed that parents who have had access to the Swedish child health care system are quite aware of the recommended lifestyle for their children in terms of food consumption, physical exercise and healthy leisure activities. The general recommendation for young children is to eat three main meals and two to three between-meal snacks per day, including a snack around 7 o'clock in the evening if dinner was at 5 . Milk, fruit and vegetables are recommended for consumption several times a day, whereas soft drinks and junk food are not encouraged. Candy is recommended to be reserved for weekends. However, the way information is perceived and processed within the family will be highly influenced by the social and cultural context, as well as personal values of the parents.

\section{Parental practices vs. attitudes}

Thus, family SES, as well as the social and cultural context, have an impact on parenting practices and the role models parents give to their children. However, we know less about the role of SES in parents' attitudes concerning the lifestyle of their children. Most studies tend to investigate actual parenting practices, whereas attitudes do not receive attention as often. An increasingly prevalent notion in the health behaviour literature, however, is that attitudes - more so than knowledge - influence behaviour. Attitudes are psychological tendencies that are expressed by evaluating a particular entity with the same degree of favour or disfavour. They are not directly observable but can be inferred from observable responses, behaviours and practices ${ }^{14}$.

One would therefore expect that differences in behaviour will be mirrored by differences in attitudes, and vice versa. Thus, given that lifestyle-related practices for their children differ between parents of high and low SES, so could lifestyle-related attitude. Therefore, investigating parental attitudes and how they do or do not become translated into actual practices depending on the family's SES can provide us with key information in terms of targets for prevention interventions. It is also of interest to obtain information on what parents consider positive and negative circumstances to reach the goals of a healthy lifestyle for their children.

\section{Methods}

\section{Subjects}

Subjects were parents of 176 pupils attending the first grade in five different schools located in a school district of Uppsala. The schools were chosen to represent different social backgrounds. Parents $(n=213)$ of 158 children had answered the questionnaire: $42 \%$ had 12 years education or less and $58 \%$ had more than 12 years of education. Parents' age was distributed as follows: 20-30 years (7.6\%), 31-40 years $(58.2 \%), 41-50$ years $(32.2 \%)$ and $51-$ 60 years $(2.0 \%)$. There were 63 (39.9\%) children who had a non-Swedish-speaking background. The study population represented $10 \%$ of the total number of 6 -year-old children in Uppsala during this particular period. The study was approved by the Ethical Committee of the Faculty of Medicine, Uppsala University, Sweden (D.no. 03-537).

\section{Instruments}

The survey included 49 questions, both structured and open-ended, divided into four sections (Table 1). The questions were formulated to examine parents' reported practices and attitudes as follows: 'How many times per week does your 6-year-old child have breakfast?' and 'How many times per week do you think that your 6-year-old child should have breakfast?', respectively. The last part of the questionnaire included questions examining possible obstacles experienced by the parents and their desired support to reach healthy lifestyle goals for their children (Table 1).

The questions concerning meal patterns and nutrition intake have been used in a previous study among children and adolescents ${ }^{15}$. In this study, the questions were altered for use with parents; a pilot study using 12 participants was performed to test the functionality of the instrument. These participants were not included in the study. Respondents in the pilot study perceived that when they had to disclose their attitudes first and then their practices, social desirability strongly influenced their answers to the latter. Therefore, the order of these questions was switched.

\section{Procedure}

The school nurse at each chosen school was informed about the study and was asked to participate. Each school nurse handed out information letters, questionnaires and a return envelope to the pupils with instructions to give these to their parents. The parents were instructed to fill in the questionnaire, put it in the envelope and return it to 
2b. Parents' reported practices of children's physical activity (exercise and organised activity)

Outdoor games and television/computer

3a. Parents' attitudes towards children's meal patterns (breakfast, lunch, snack, dinner, evening snack) Parents' attitudes towards children's intake of fruit, vegetables, milk and crisps/candy

3b. Parents' attitudes towards children's physical activity (exercise and organised activity)

Outdoor games and television/computer

4a. Desired support for parents to give their children healthy meals and enough physical activity

4b. Experienced obstacles to parents giving their children healthy meals and enough physical activity
Possible answers

e.g. Education:

(a) Primary school

(b) Secondary school

(c) College/University

(d) Folk high-school

(e) Other

$5 \quad$ Never (0) to seven (7) days per week

(a) Never

(b) Once a week

(c) Several times a week

(d) Every day

(e) Several times a day

(a) Never

(b) Once every other month

(c) 1-3 times per week

(d) Once a week

(e) Several times per week

(a) $0-1 \mathrm{~h}$ per day

(b) $1-2 \mathrm{~h}$ per day

(c) $2-3 \mathrm{~h}$ per day

(d) 3-4 $\mathrm{h}$ per day

(e) $>4 \mathrm{~h}$ per day

$5 \quad$ Never (0) to seven (7) days per week

(a) Never

(b) Once a week

(c) Several times a week

(d) Every day

(e) Several times a day

(a) Never

(b) Once every other month

(c) 1-3 times per week

(d) Once a week

(e) Several times per week

(a) $0-1 \mathrm{~h}$ per day

(b) $1-2 \mathrm{~h}$ per day

(c) $2-3 \mathrm{~h}$ per day

(d) $3-4 \mathrm{~h}$ per day

(d) $3-4 \mathrm{~h}$ per day
(e) $>4 \mathrm{~h}$ per day

(e) $>4 \mathrm{~h}$ per day

Open question: What kind of support do you desire to give your child healthy meals and enough physical actitity?

4 Open questions: e.g. What kind of support do you want in order to give your child healthy meals and enough physical activity?

$n-$ number of questions. 
the school nurse via the pupil. The letters contained information about the study, that participation was voluntary and approved by the Ethical Committee, and that the questionnaires were coded. The reason for the code was to make it possible to send out a reminder. Reminders were sent to $38.6 \%$ of the families, and of the 68 reminders 50 questionnaires were filled in and returned to the school nurses, giving a total response rate of $89.7 \%$. More than half (62\%) of the questionnaires were filled in by the mothers, a third (34\%) by both parents and $4 \%$ by the fathers.

\section{Data analyses and statistical methods}

Educational levels were merged into two groups: one contained parents with 12 years education or less (secondary school level) and the other group contained parents with more than 12 years education (college degree level). The number of meals per week was used as scale variable, whereas dummy variables were constructed for ordinal variables. Descriptive statistical methods were used to examine the answers to the structured questions, and independent $t$-tests were used to clarify differences between the groups and concerning the frequency of different meals. Fischer's PLSD (protected least significant difference) was used as a post hoc test to verify the significance of the dependent $t$-tests. Mann-Whitney $U$-tests were used to clarify differences in nutrition intake and physical activity between the two groups.

Reported obstacles and need of support were initially dichotomised into having reported any of the above or not. Then a qualitative content analysis was employed to examine the answers to the open-ended questions concerning the parents' thoughts about obstacles and their need for support ${ }^{16}$. The method we employed was manifest content analysis, designating categories based on the exact expressions used by the respondents ${ }^{17}$. We then assigned a number to each of these categories and treated them as dummy variables in the statistical analyses. Thus, the given numbers did not actually have numeric qualities, but were a tool to convert the qualitative data into a statistically useful format. $\chi^{2}$ tests were used to examine differences in experienced obstacles and desired support between the two groups with different levels of education. Linear regression equations were constructed, with reported meal patterns practices as dependent variables.

\section{Results}

\section{Meal patterns, nutrition intake and physical activity} Parents with a college degree reported that their 6-yearolds had all meals (except dinner) significantly more often during a week than did parents with only secondary school education. However, no significant differences were found in attitudes concerning these meals (Table 2). Thus, less educated parents also thought that their children should be eating breakfast, lunch and a daytime snack every day, but this was not reflected in their reported practices.

For the other items concerning lifestyle, significant differences were found in both reported practices and attitudes between the two parental educational groups (Table 3). Children of parents with a college degree had junk food less often, milk, fruit and vegetables more often, did more exercise and organised activities, and played more outdoor games than children of parents with only a secondary school education. Hours reported spent watching television both for weekdays and weekends were more for the less educated parental group. The difference in reported practices was reflected in parents' attitudes towards milk, fruit and vegetable consumption, exercise and television viewing on weekdays. Thus, parents with only a secondary school education thought that their children did not need to drink milk, eat fruit and vegetables, and exercise as often as was thought by the parents in the college degree group. Two-thirds of the parents in the less educated group thought $1-2 \mathrm{~h}$ of television on weekdays was fine, whereas the majority of parents in the well-educated group thought $0-1 \mathrm{~h}$ daily to be the most suitable for their children. However, there was no statistical difference between attitudes to junk food, desired frequency of organised activities, outdoor games and television viewing on weekends (Table 3).

Table 2 Differences between parents of different education levels regarding their reported practices and attitudes to their childrens' meal pattern; means (standard deviation) for to what extent the child ate/should eat the meals of the day weekly

\begin{tabular}{lcccc}
\hline & $\begin{array}{c}\text { Parents } \\
\text { with }<12 \text { years education }\end{array}$ & $\begin{array}{c}\text { Parents } \\
\text { with } \geq 12 \text { years education }\end{array}$ & $t$ & $P$ \\
\hline Breakfast practice & $4.8(2.4)$ & $6.8(1.0)$ & $07: 02$ & 0.0001 \\
Breakfast attitude & $6.9(0.7)$ & $7.0(0)$ & $01: 09$ & $\mathrm{NS}$ \\
Lunch practice & $6.2(1.4)$ & $6.8(0.7)$ & $03: 53$ & 0.0005 \\
Lunch attitude & $6.9(0.5)$ & $6.9(0.4)$ & $01: 18$ & $\mathrm{NS}$ \\
Snack practice & $6.1(1.6)$ & $6.7(0.7)$ & $03: 18$ & 0.002 \\
Snack attitude & $6.9(0.6)$ & $6.9(0.5)$ & $00: 02$ & $\mathrm{NS}$ \\
Evening snack practice & $3.3(2.9)$ & $4.4(2.8)$ & $02: 49$ & 0.01 \\
Evening snack attitude & $5.4(2.7)$ & $4.4(3.3)$ & $01: 09$ & $\mathrm{NS}$ \\
\hline
\end{tabular}

NS - non-significant. 
Table 3 The most common frequency (mode) and $P$-value for some nutrition intake and physical activities in the two educational groups

\begin{tabular}{|c|c|c|c|c|}
\hline & & $<12$ years education & $\geq 12$ years education & $P$ \\
\hline \multirow[t]{2}{*}{ Milk } & Practice & $58.2 \%$ every day & $38.5 \%$ several times per day & 0.001 \\
\hline & Attitude & $77.6 \%$ every day & $45.0 \%$ several times per day & 0.006 \\
\hline \multirow[t]{2}{*}{ Candy/crisps } & Practice & $68.2 \%$ several times per week & $91.0 \%$ once/twice per week & 0.0001 \\
\hline & Attitude & $97.0 \% 1-2$ times per day & $98.8 \%$ once/twice per week & NS \\
\hline \multirow[t]{2}{*}{ Fruit } & Practice & $44.8 \%$ every day & $49.5 \%$ every day & 0.001 \\
\hline & Attitude & $77.6 \%$ every day & $58.2 \%$ several times per day & 0.0001 \\
\hline \multirow[t]{2}{*}{ Vegetable } & Practice & $65.7 \%$ several times per week & $35.2 \%$ every day & 0.0001 \\
\hline & Attitude & $73.1 \%$ every day & $50.6 \%$ several times per day & 0.0001 \\
\hline \multirow[t]{2}{*}{ Exercise } & Practice & $25.4 \%$ once per week & $35.6 \%$ once a week & 0.0002 \\
\hline & Attitude & $47.8 \%$ once per week & $72.5 \%$ several times per week & 0.0001 \\
\hline \multirow[t]{2}{*}{ Organised activity } & Practice & $28.4 \%$ once a week & $51.7 \%$ once a week & 0.0001 \\
\hline & Attitude & $67.2 \%$ once a week & $68.1 \%$ once a week & NS \\
\hline \multirow[t]{2}{*}{ Outdoor games } & Practice & $49.3 \% 1-2 \mathrm{~h}$ per day & $64.8 \% 1-2 \mathrm{~h}$ per day & 0.0001 \\
\hline & Attitude & $38.8 \% 1-2 \mathrm{~h}$ per day & $42.9 \% 2-3 \mathrm{~h}$ per day & NS \\
\hline \multirow[t]{2}{*}{ TV/computer (weekday) } & Practice & $37.3 \% 1-2 \mathrm{~h}$ per day & $40.7 \% 0-1 \mathrm{~h}$ per day & 0.0001 \\
\hline & Attitude & $68.7 \% 1-2 \mathrm{~h}$ per day & $56.0 \% 0-1 \mathrm{~h}$ per day & 0.0001 \\
\hline \multirow{2}{*}{ TV/computer (weekend) } & Practice & $43.4 \%>4 \mathrm{~h}$ per day & $49.5 \% 2-3 \mathrm{~h}$ per day & 0.0001 \\
\hline & Attitude & $49.3 \% 1-2 \mathrm{~h}$ per day & $55.0 \% 1-2 \mathrm{~h}$ per day & NS \\
\hline
\end{tabular}

TV - television; NS - non-significant by Mann-Whitney U-test.

\section{Experienced obstacles}

In total, 122 (69.3\%) parents reported that their child did not eat enough healthy meals and did not get enough physical exercise, due to experienced obstacles. Of the parents who experienced obstacles, 53 (43.4\%) had secondary school level education and $69(56.6 \%)$ had a college degree (not significant). The obstacles were categorised into five different groups through manifest content analysis: child being fastidious; lack of time; lack of money; lack of time in combination with lack of money; and lack of time in combination with the fact the child did not want to play outdoors but preferred television/computer. The sixth group was those parents who did not experience any obstacles.

When comparing the kind of obstacles reported by the two parental groups, significant differences emerged. More parents with a higher education stated lack of time as the most common obstacle, compared with parents with lower levels of education, who stated lack of money and lack of time in combination with lack of money as their most common obstacles $(P<0.001)$. Significantly more parents with a high level of education reported that the behaviour and fastidiousness of the child was part of the reason for the children not having enough healthy meals and physical exercise, e.g. that the child did not want to play outdoors, but preferred the television/computer $(P<0.001)$.

Examining Swedish- and non-Swedish-speaking parents, the former significantly more often stated lack of time and behaviour of the child as their most common obstacle. Non-Swedish-speaking parents, on the other hand, more often cited lack of money as the most common obstacle in reaching healthy lifestyle goals for their children $(P<0.005)$.

\section{Desired support}

There were 104 parents (59.1\%) who stated a need for support in order to be able to give their children healthy meals and enough physical activity. The figures were fairly evenly divided between the education groups: 48 (46.2\%) of parents with secondary school examinations and 56 (53.8\%) of parents with a college degree stated a need for support (not significant). The desired support was categorised into six groups: more physical activity in school; shorter working day; domestic help; better food at school; more teaching about food and physical activity at school; and economic support. The seventh group described no need for support. There was no significant difference between the two parental groups and, irrespective of educational background, parents identified the school as the most commonly desired source of support. When desired support from the school was disregarded in the analysis, parents with lower levels of education significantly more often desired shorter working days and economic support, compared with parents with a higher education, who significantly more often desired domestic help $(P<0.04)$. Examining Swedish- and non-Swedish-speaking parents, Swedish-speaking parents significantly more often desired support from the school and domestic help compared with non-Swedish-speaking parents who significantly more often desired economic support $(P<0.009)$.

\section{Linear regression analyses}

Linear regression equations were constructed to explain the variance in reported practices for the different meals of the day, given that the explanation did not seem to be differing attitudes of the parents in the two different groups. Our main question was whether there were variables other than educational level that independently predicted meal patterns.

The best explained variance in reported meal patterns was for eating breakfast $\left(R^{2}=0.51\right)$. Parental higher education and frequency of milk drinking were positively 
related to a higher frequency of eating breakfast. Factors having a negative impact on frequency of eating breakfast were: non-Swedish-speaking background, reported $\geq 3 \mathrm{~h}$ of television viewing on weekdays, and reporting any kind of hindrance to healthy lifestyle choices for children. Eating lunch as a dependent variable was also positively affected by parents' educational level, but not the other meal patterns, i.e. dinner and snacks. Other variables positively influencing frequency of lunch, snacks and dinner per week were parents' perception of being able to provide their children with healthy food habits and less time allowed for television viewing daily. Thus, feelings of not being able to provide the child with healthy meals had an independent negative effect on healthy food behaviour practices, as did allowing children to view television for $\geq 3 \mathrm{~h}$ per day.

Fruit intake was influenced by parents' perception of being able to provide their children with healthy food habits, and vegetable intake by the amount of allowed television/computer time. As expected, parental educational level and television viewing were highly correlated $(r=0.33$ for $0-1 \mathrm{~h}$ per day and $r=-0.405$ for $3-4 \mathrm{~h}$ per day for the group with higher education).

In summary, the regression equations supported the notion that parental education has an independent effect on the frequencies of eating breakfast and lunch (Table 4). However, the effect of parental education seemed to be mediated by television viewing for the other meal patterns as well as for vegetable intake.

An additional variable, parents' perception of being able to provide their children with healthy eating habits proved to be an independent predictor of frequencies of eating lunch, snacks and dinner, and fruit intake. Notably, this perception was not significantly correlated with parental education and thus cannot be treated as a kind of proxy for parental education, as seems to be the case with television viewing. Interestingly, those who perceived that they had the ability to provide their children with healthy eating habits reported significantly more obstacles compared with those who did not feel that they had this ability $(P$ $<0.003)$.

\section{Discussion}

\section{The congruence and incongruence of parental attitudes and reported practices}

There was a significant difference between the two parental education groups, with all examined lifestyle choices conducive to health in children being more common among the group with more years of education. The results are in agreement with those of a study in Stockholm of 9-year-olds showing that children in poorer areas took part in organised activities less often and spent more time using a television or computer ${ }^{18}$. It is also established in the existing literature that higher levels of education in parents correlate with healthier patterns of

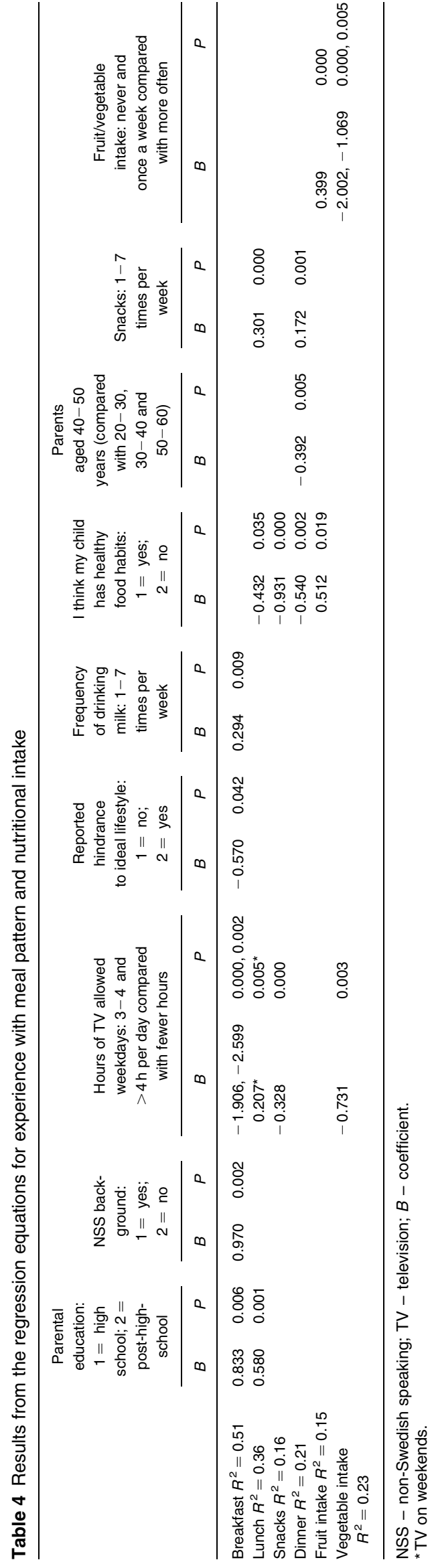


nutrition intake and physical activity in children. Also, when taking different social and cultural factors into account, parents' academic competence seems to be significant for both healthier eating patterns and for knowledge of food and nutrition ${ }^{19,20}$.

The difference in reported practices was mirrored by parental attitudes regarding fruit and vegetable consumption, hours of exercise and hours allowed for television and computer use on weekdays. Thus, reported practices in these areas were congruent with parents' attitudes. What is intriguing in our results is that the different practices for meal patterns, organised activity and outdoor games, consumption of junk foods, and hours allowed for television and computer use on weekdays were not accompanied by differences in parental attitudes between the two educational levels. Reported practices in these areas were, thus, not congruent with parents' attitudes.

It seems quite clear from the above that depending on whether parental attitudes and practices are congruent or not, different types of interventions are suitable. Where parental attitudes show a preference for less healthy lifestyle choices, such as, for example, for fruit and vegetable consumption in this study, interventions addressing knowledge and attitudes might be needed. For lifestyle areas where parents seem aware of and are positive towards healthy choices, the specific obstacles and issues of parenting self-efficacy might need to be addressed. In any case, it seems a fruitful approach to assess both attitudes and reported practices when examining young children's lifestyles.

\section{Experienced obstacles and parenting self-efficacy}

Seventy per cent of participating parents experienced obstacles in reaching the desired goals for achieving a healthy lifestyle for their children, with lack of time as the main obstacle. Although there was no difference between the proportion of parents reporting obstacles between the two educational groups, significantly more parents with a lower education perceived lack of money or the latter in combination with lack of time to be the main issue. An explanation for this pattern might of course be that lower educational levels lead to jobs with lower wages and less influence on work hours.

For those with a higher education, lack of time was the most important obstacle, and the answers indicate that these parents would willingly trade their current hours performing household tasks to engage more with their children.

The concept of self-efficacy is a perception of one's ability to perform competently and effectively at a particular task or in a particular setting ${ }^{21}$. People with a high sense of self-efficacy will persist in a given task, whereas low self-efficacy is related to giving up prematurely. Interestingly, those parents who felt they were able to provide their child with healthy eating habits, i.e. felt successful in this particular area, reported significantly more obstacles compared with those who felt they were not, for each hindrance category. Our question on the perceived ability to provide the child with healthy eating habits might thus be tapping into parenting self-efficacy. The 'Control', 'Boundaries' and 'Routine' subscales described in Kendall and Bloomfield's parenting self-efficacy instrument ${ }^{22}$ seem conceptually related to this item. Given the influence of this single variable on the majority of food-related practices (Table 4), it certainly seems to reflect a central mechanism influencing parenting practices.

What then is the relationship between educational background and parenting self-efficacy? Educational background explained $20-25 \%$ of the variance for most subscales in the parenting self-efficacy instrument of Kendall and Bloomfield ${ }^{22}$. In this study, parents with a lower education did not succeed in implementing practices according to their attitudes regarding most of the lifestyle items examined. It might well be that parents with lower education lack the self-efficacy required to implement their views. However, although parenting selfefficacy and educational background are interrelated, less education does not necessarily mean less self-efficacy. In this study, there was no difference depending on educational background in the perception of being able to provide the child with healthy eating habits. Neither was there a difference between experiencing obstacles on the whole. However, the type of obstacles differed. It is possible, therefore, that certain obstacles weigh more in the final pathway leading from knowledge through to attitudes to behavioural practices, where self-efficacy is a key element to success, as pointed out in a recent Cochrane review ${ }^{23}$.

We do not claim to have measured parenting selfefficacy adequately in this study. Our aim with this discussion is to highlight the fact that parental attitudes did not differ between the educational groups for most of the lifestyle areas examined, whereas reported practices did. The explanation for this pathway was, thus, not differences in education or even knowledge per se, but rather something that could be seen as a confounder. A combination of practical obstacles perceived as serious and (possibly resulting) low parenting self-efficacy are both factors to do with educational level and the outcomes examined. Although there is certainly much more to learn about this topic, it is important to realise that most parents with less education in this study wanted the same for their children as those with higher formal qualifications, but the possibilities of putting attitudes into practices seemed to differ for these two groups.

\section{Methodological considerations}

The fact that the parents were asked to state both their attitudes and their practices might produce moral difficulties. To admit that you have not given your child what you believe is appropriate can be hard and may have influenced the results. There is also the issue of 'social 
desirability', a term that refers to respondents giving answers that they think are expected from them. By asking parents to describe both their attitudes and practices, the social desirability of answers to reported practices might have been reduced, as indicated by our pilot study, whereas reported attitudes might certainly be affected. In addition, among parents of foreign origin, poor understanding of the subtle difference between the two lines of questions might have influenced the answers.

Although the response rate in the study was excellent, among the 18 parents (10\%) who did not respond only $1 \%$ were from a school where the majority of parents had a college degree, while the schools where parents had a lower level of education had a higher drop-out rate.

Combining qualitative and quantitative methods in the same study and especially the same analysis is still considered contradictory by some researchers. Converting the categories to dummy variables was a useful strategy employed elsewhere ${ }^{24}$ and did not change the character of the data as the texts were not actually quantified. By using two researchers to categorise the material (C.S. and A.S.), the credibility of the findings was increased ${ }^{25}$.

\section{Limitations}

The questionnaire failed to differentiate between television viewing and time spent playing computer games. Current evidence strongly suggests that television viewing is associated with childhood obesity and aggressive play in children. However, studies thus far have not incriminated computer and video games in this aspect. In fact, it seems that computer and video games increase spatial intelligence $^{26}$. Thus, it is important to separate television viewing from playing video and computer games in future studies.

The context of the study is Sweden, a comparatively equitable society, where social policies explicitly have worked against social inequities for at least half a century. This means that the living standards and wages do not differ as sharply between the educational groups. The special strength of the study is, however, that $40 \%$ of participants had a non-Swedish-speaking background, which is more than in the population as a whole. This would in fact increase the generalisability of the findings for other cultural contexts.

\section{Conclusion}

The main result of the study was that parents' reported practices for their 6-year-old children regarding meal patterns, nutrition intake and lifestyle behaviours differed due to educational background but this was not shown to the same extent with regard to their attitudes. Thus, it seems to be a fruitful approach to assess parents' reported practices and attitudes as well as perceived obstacles before different types of interventions are decided upon to attain healthy lifestyle habits in children.

\section{Acknowledgements}

Sources of funding: A.S. was supported through a personal research grant from the Swedish council for working life and social research, grant no. 2002-0940.

Conflict of interest declaration: The authors declare that there has been no conflict of interest in conducting the study.

Authorship responsibilities: C.S. was responsible for data collection, carried out the descriptive and correlational data analyses, and participated in discussions of the focus of the manuscript as well as in writing the manuscript. A.S. conceived the idea and focus of the manuscript, carried out the regression analyses and participated in writing the manuscript. B.E. was responsible for the study design, including the modification of the questionnaire used, tutored C.S. through data analysis, and participated in discussions of the focus of the manuscript as well as in writing the manuscript.

\section{References}

1 Klesges R, Klesges L, Eck L, Shelton M. A longitudinal analysis of accelerated weight gain in preschool children. Pediatrics 1995; 95: 126-30.

2 Freedman DS, Khan LK, Serdula MK, Dietz WH, Srinivasan SR, Berenson GS. The relation of childhood BMI to adult adiposity: the Bogalusa Heart Study. Pediatrics 2005; 115: $22-7$.

3 Hesketh K, Wake M, Waters E, Carlin J, Crawford D. Stability of body mass index in Australian children: a prospective cohort study across the middle childhood years. Public Health Nutrition 2004; 7: 251-2.

4 Guo SS, Wu W, Chumlea WC, Roche AF. Predicting overweight and obesity in adulthood from body mass index values in childhood and adolescence. American Journal of Clinical Nutrition 2002; 76: 653-8.

5 He Q, Karlberg J. Probability of adult overweight and risk change during the BMI rebound period. Obesity Research 2002; 10: 135-40.

6 van de Mheen H, Stronks K, Looman C, Mackenbach J. Does childhood socioeconomic status influence adult health through behavioural factors? International Journal of Epidemiology 1998; 27: 431-7.

7 Power C, Graham H, Due P, Hallqvist J, Joung I, Kuh D, et al. The contribution of childhood and adult socioeconomic position to adult obesity and smoking behaviour: an international comparison. International Journal of Epidemiology 2005; 34: 335-44.

8 Ebrahim S, Montaner D, Lawlor DA. Clustering of risk factors and social class in childhood and adulthood in British women's heart and health study: cross sectional analysis. British Medical Journal 2004; 328: 861.

9 Gibson E, Wardle J, Watts C. Fruit and vegetable consumption, nutritional knowledge and beliefs in mothers and children. Appetite 1998; 31: 205-28.

10 Rogers I, Emmett P, ALSPAC StudyTeam. The effect of maternal smoking status, educational level and age on food and nutrient intakes in preschool children: results from the Avon Longitudinal Study of Parents and Children. European Journal of Clinical Nutrition 2003; 57: 854-64.

11 Cooke L, Wardle J, Gibson E, Sapochnik M, Sheiham A, Lawson M. Demographic, familial and trait predictors of fruit 
and vegetable consumption by pre-school children. Public Health Nutrition 2004; 7: 295-302.

12 Crawford PB, Obarzanek E, Schreiber GB, Barrier P, Goldman S, Frederick MM, et al. The effects of race, household income, and parental education on nutrient intakes of 9- and 10-year-old girls NHLBI growth and health study. Annals of Epidemiology 1995; 5: 360-8.

13 Hart KH, Herriot A, Bishop JA, Truby H. Promoting healthy diet and exercise patterns amongst primary school children: a qualitative investigation of parental perspectives. Journal of Human Nutrition and Dietetics 2003; 16: 89-96.

14 Eagly HA, Chaiken S. The Psychology of Attitudes. Orlando, FL: Harcourt Brace College Publishers, 1993.

15 Edlund B. Dieting in Swedish Children and Adolescents. Doctoral Thesis. Acta Universitatis Upsaliensis. Uppsala, 1997.

16 Graneheim UH, Lundman B. Qualitative content analysis in nursing research: concepts, procedures and measures to achieve trustworthiness. Nurse Education Today 2004; 24: 105-12.

17 Woods L, Priest H, Roberts P. An overview of three different approaches to the interpretation of qualitative data. Part 2: practical illustrations. Nurse Researcher 2002; 10: 43-51.

18 Callmer E, Bonnevier H, Jälminger A-K, Azriela M. Sociala skillnader i övervikt, fysiska aktivitet och matvanor bland 9åriga barn i Stockbolms läns landsting [Social Differences in Overweight, Physical Activity and Food Habits among 9-year old Children in Stockholm County]. Rapport. Stockholm: Centrum för Tillämpad Näringslära Samhällsmedicin, Stockholms läns landsting, 2002.
19 Djuric Z, Faye Cadwell W, Heilbrun LK, Venkatramanamoorthy R, Dereski MO, Lan R, et al. Relationships of psychosocial factors to dietary intakes of preadolescent girls from diverse backgrounds. Maternal and Child Nutrition 2006; 2: 79-90.

20 Ivanovic D, Castro CG, Ivanovic R. Food and nutrition knowledge of school-age children's mothers from elementary and high school from different socioeconomic levels. Archives of Latinoamerican Nutrition 1997; 47: 248-55.

21 Bandura A. Self-efficacy mechanism in human agency. American Psychologist 1982; 37: 122-47.

22 Kendall S, Bloomfield L. Developing and validating a tool to measure parenting self-efficacy. Journal of Advanced Nursing 2005; 51: 174-81.

23 Murray E, Burns J, See Tai S, Lai R, Nazareth I. Interactive health communication applications for people with chronic disease. Cochrane Database of Systematic Reviews 2005.

24 Vég A, Rosenqvist U, Sarkadi A. Self-management profiles and metabolic outcomes in type 2 diabetes. Journal of Advanced Nursing 2006; 56: 1-11.

25 Sandelowski M. The problem of rigour in qualitative research. Advanced Nursing Sciences 1986; 8: 27-37.

26 Lager A, Bremberg S. Hälsoefekter av tv-och datorspelande. En systematisk genomgång av vetenskapliga studier [The bealth effects of $T V$ - and computer games. A systematic review]. Report No. 2005:18. Stockholm: National Institute of Public Health, 2005. 